\section{LA INDUSTRIA DEL CÓMIC EN ESPAÑA: RADIOGRAFÍA DE ¿UN MITO O UNA REALIDAD?}

\author{
Álvaro M. Pons \\ Profesor de Óptica en la Universidad de Valencia, \\ crítico de cómic y director del blog 'La Cárcel de Papel'
}

\section{THE INDUSTRY OF THE CARTOON STORIES IN SPAIN. AN X-RAY OF MYTH OR REALITY?}

\begin{abstract}
In spite of the importance of figures referred to published titles, or number of copies printed, which help to set publishing strategies and to really know the comic situation in Spain, there are no liable data. We are giving in this article, some enlightening data along with some explanations related to the evolution of the market from 2001 to 2009. The different titles are grouped considering the place they come from (Europe, Asia, United States...), along with their format (album, book, magazine, comic-book...). Using all this information, we can deduce evolution lines, tendencies, futures perspectives in an industry that, despite its precariousness, is facing an increasing number of copies sold and a progressive settlement in the Spanish publishing world.
\end{abstract}

KEY WORDS: Market, industry, formats, sales, editions and print-run, percentages, Spanish production, import-export.

\section{INTRODUCCIÓN}

El cómic es una forma de cultura popular de singular importancia en España. Convertido durante los años cuarenta en la principal forma de entretenimiento popular, ha evolucionado de forma radical durante los últimos 70 años, adaptándose a las necesidades tanto comerciales como artísticas a partir de profundos cambios estructurales del tejido industrial creado a su alrededor.

Pese a la falta de datos objetivos referentes a cuestiones comerciales, solo se puede abordar una perspectiva completa de estudio del cómic en España si se añade la componente industrial de este arte. El objetivo de este trabajo es hacer un amplio repaso a la evolución de ese sector desde la perspectiva industrial, con especial énfasis en lo ocurrido en la primera década del siglo XXI.

No se puede establecer ningún estudio en profundidad de la realidad del cómic en España sin atender a su vertiente industrial. La historieta se establece definitivamente como forma artística y cultural durante el siglo XX, profundamente entroncada dentro de la cultura popular
RESUMEN: A pesar de la importancia que revestiría para establecer estrategias editoriales y para un mejor conocimiento de la situación del cómic en España, no existen cifras fiables sobre títulos publicados y cifras de tiradas. En este artículo se proporcionan algunos datos aclaradores al respecto. Se ofrece una evolución de nuestro mercado desde 2001 a 2009. Se agrupan los diversos títulos por lugar de procedencia (Europa, Asia, Estados Unidos...), así como por formatos (álbum, libro, revista, comic-book...). De todo ello se desprenden líneas evolutivas, tendencias y perspectivas de futuro de una industria que, a pesar de su precariedad, conoce un aumento de las ventas y un progresivo asentamiento en el panorama de la edición española.

PALABRAS CLAVE: Mercado, industria, formatos, ventas, tiradas, porcentajes, producción española, importación-exportación.

y asumiendo la dualidad entre forma de entretenimiento y artística común a otras artes nacidas en esa centuria. Una dicotomía que está en la base de todo el debate que el llamado noveno arte ha generado desde su propia definición, todavía incompleta y sujeta a cambios continuos que vienen en muchos casos derivados por las tensiones que provoca su afiliación como producto infantojuvenil. Sin embargo, independientemente de las agrias polémicas y problemas de autoidentidad que adolece continuamente la historieta, solo se puede abordar una perspectiva completa de su estudio si se añade la componente industrial. Como indica el historiador Antonio Martín, "el cómic solo es reconocible como realidad social si se tienen en cuenta los aspectos industriales y económicos que están en la base de su misma existencia pública" (Martín, 2003).

Sin embargo, esta necesidad epistemológica a la hora de establecer cualquier estudio sobre la historieta en España choca con la casi absoluta ausencia de datos reales y fidedignos sobre la evolución de la industria del tebeo español. Pese a la profunda importancia y clara imbricación del tebeo en el imaginario popular español, que hace sospechar 
una espectacular difusión y, por lo tanto, la existencia de un sector económicamente importante, no existen datos que puedan informar de tiradas, ventas o porcentajes dentro del sector editorial. Incluso los únicos datos oficiales, provenientes de los estudios de Comercio Interior del Libro que realiza la Federación de Gremios de Editores de España desde el año 19991, deben ser puestos en cuarentena en lo que afecta a los datos del sector del tebeo, ya que muchas de las cifras que ofrece entran en contradicción por las proporcionadas por otros organismos oficiales como la Federación de Industrias del Cómic (FICOMIC).

Esta dificultad establece que todo análisis que se haga sobre la evolución de la industria del cómic en España es, obligatoriamente, cualitativo y sujeto a revisión. Los datos que se pueden obtener no dejan de ser comunicaciones personales 0 datos muy dispersos que no están validados por referentes externos como pueden ser las empresas destinadas a la justificación de difusión, por lo que su veracidad no es comprobable. En cualquier caso, el estudio, aunque solo sea cualitativo, puede ser útil en tanto puede dar un panorama reconocible en su conjunto y globalidad.

\section{EL NACIMIENTO DE UNA CULTURA DE MASAS}

Tras una brillante eclosión de la industria del cómic durante la dictadura de Primo de Rivera y la II República y siempre desde la perspectiva de una publicación cuyo destino era el público infantil y juvenil (Martín, 1978), la guerra civil supuso un brutal parón que dejaría una industria prácticamente descabezada que tuvo que enfrentarse a graves problemas para su recuperación durante la dictadura franquista. Por un lado, las dificultades económicas para la consecución de papel, que derivaron en estrictas normas de autorización de publicaciones periódicas (Martín, 2000), agravadas por la política de favorecimiento de publicaciones afines al régimen. Por otro la férrea censura previa a la que estaba sometida cualquier publicación (Porcel, 2004) limitaba y coartaba tanto en lo creativo como en lo comercial el tipo de publicaciones. Sin embargo, pese a las limitaciones, la implantación y crecimiento del tebeo como forma cultural popular es espectacular. Como indica Alexander
Cirici: "[...] las publicaciones infantiles ilustradas representaron en los años cuarenta y gran parte de los cincuenta el factor cultural y la presencia artística más considerable de la vida en el Estado español" (Cirici, 1977). Una situación idónea para que el tebeo afrontase la entrada en la década de los cincuenta como un producto de cultura de masas en toda su extensión (Moix, 1968), basado fundamentalmente en el éxito de dos formatos de publicación (Porcel, 2002): por un lado, la revista, heredera del formato clásico de suplemento nacido en los diarios y que se centraba fundamentalmente en contenidos cómicos infantiles y que tendrían como ejemplos más exitosos títulos como Pulgarcito, Jaimito o TBO. En el otro lado, el cuadernillo de aventuras, un formato apaisado de pocas páginas importado de Italia que se establece rápidamente por una afortunada combinación: es un producto barato, que se adapta perfectamente a las dificultades de producción y escasez de la época y, sobre todo, aporta una temática exótica de evasión que es aceptada por un lector sujeto a no pocas penurias (Pons, 2006). En ese contexto, los datos que se pueden obtener dan una idea de la extensa difusión que tendrían estas revistas: la publicación Chicos consiguió llegar hasta los 115.000 ejemplares de tirada a finales de los cuarenta, mientras que el fundacional TBO podría alcanzaba en esas fechas ventas cercanas a los 225.000 ejemplares, que llegarían al techo de 350.000 en 1952 (Martín, 2000). Por su parte, los cuadernos de aventuras gozan de una popularidad creciente aprovechada fundamentalmente por Editorial Valenciana, que gracias al éxito de Roberto Alcázar y Pedrín irá aumentando el número de series publicadas año a año, con tiradas que llegarán a los impresionantes 200.000 ejemplares semanales de El Guerrero del Antifaz (Porcel, 2002), con un total de más de 4.500 títulos editados en 1945 (Martín, 2002), siempre distribuidas a través de la extensa red de quioscos de prensa. El éxito se transforma en una amplia estructura industrial diseminada por todo el Estado español, con tres vórtices fundamentales de concentración: Barcelona (con la clara prevalencia de las editoriales Bruguera, Toray e Hispano Americana de Ediciones), Valencia (con las editoriales Maga, Guerri y Valenciana) y Madrid (con Gil, Ediciones Recretivas y las publicaciones de las FET y de las J ONS, entre otras), en su gran mayoría evolucionadas desde estructuras empresariales familiares y con el debe del trato al autor, del que no se respetan ni la autoría intelectual ni los derechos. 
La aparición de títulos como El Capitán Trueno en 1956 solo cambiaría los equilibrios de poder entre editoriales, decantándose por la supremacía de una editorial, Bruguera, que prácticamente implantaría un monopolio durante los años sesenta y setenta.

\section{EL CAMBIO DE LOS AÑOS SESENTA}

La estable estructura editorial creada alrededor de la popularidad del tebeo durante los años cuarenta y cincuenta comenzaría a tambalearse durante la década de los sesenta. Las mejoras socioeconómicas aportadas por la década del desarrollismo, junto con un tímida apertura por parte de la censura permitió que la hasta entonces preponderancia absoluta del tebeo de producción nacional fuese lentamente erosionada por la importación de series extranjeras. Editoriales como Hispanoamericana o Dólar comienzan a editar en distintos formatos (incluyendo un seminal "Novela gráfica") series provenientes de la prensa americana, como Flash Gordon o El Hombre Enmascarado, compitiendo abiertamente con un modelo de publicación que comenzaba a quedar caduco en unos lectores que comenzaban a abrirse a nuevas modas de entretenimiento y pensamiento como las que traía la novedosa televisión (Pons et al., 2007). Hay que añadir en este panorama la aparición de la competencia extranjera con la implantación en España de la editorial mexicana Novaro, que importaba las ediciones de los comic-books americanos de la editorial DC. Poco a poco, el formato cuadernillo apaisado en blanco y negro va desapareciendo, sustituido por el vertical de revista, ya a todo color (en muchos casos adaptando las antiguas series en cuadernillo con remontajes y recoloreados atroces) y las grandes editoriales de la década anterior se han reconvertido o directamente desaparecido, dejando a Bruguera en una posición de práctico monopolio. A mediados de los sesenta, aparecen mensualmente unos 80 títulos (Martín, 2000), la mayoría de ellos publicados por la editorial catalana.

Según los datos expuestos por Joan Navarro (1985), se pasó de 37 editoriales en 1959, que publicaron 141 series, a 32 con tan solo 59 series en 1968, con una tirada aproximada total de 5.000 .000 de ejemplares, que demuestran ya la bajada de ventas del cuadernillo frente a la buena salud del formato revista de humor.
Solo a finales de los años sesenta comienzan a aparecer tímidamente revistas con una intencionalidad más juvenil 0 incluso adulta (Trinca, Gaceta Junior, Dossier Negro), que avanzarían los profundos cambios que se darían durante la década siguiente.

\section{De LA REBELIÓN DE LOS SETENTA AL 'BOOM' DEL CÓMIC ADULTO DE LOS OCHENTA}

La hegemonía industrial de Bruguera tendrá fecha de caducidad: la muerte del dictador Franco provoca un profundo cambio social que afectará profundamente a una publicación que es vista por muchos como un remanente del antiguo régimen. El carácter infantil de las publicaciones de historieta, junto con el juicio ideológico al que se ven sometidas las series de la época (Altarriba, 2000) establece las bases de un espectacular vuelco de la distribución de la industria del tebeo en España. Bruguera sigue manteniendo una posición preferente en cuanto a revistas infantiles, pero aparecen dos nuevos formatos que darán lugar a un drástico cambio: por un lado, la editorial Vértice distribuye los comic-books de la editorial Marvel en un formato de tomo en blanco y negro (con remontajes inexplicables de la obra original) que evolucionaría al de revista en blanco y negro que incluirá varios comic-books americanos 0 partes de ellos. Por otro, la revista de cómics para adultos comienza a expandirse durante los años setenta de forma irreversible, tanto en su forma de revista satírica de gran éxito entre un público lector ávido de aperturismo (con El Papus como principal referente), como en la de revista de género: Ibero Mundial de Ediciones importa durante la primera parte de los setenta las publicaciones de la editorial americana Warren (denominadas en España Vampus, Rufus, Spirit o VampireIla), conformando una base de público que sentaría el cambio que se daría en los años ochenta. En 1976, se publican 76 cabeceras, con unas ventas conjuntas de más de 7.000.000 de ejemplares (Beaumont, 1976).

A finales de los años setenta, la editorial Nueva Frontera importa el formato revista que tanto éxito tiene en Italia y Francia con las revistas Totem, Blue Jeans y Bumerang, dando el pistoletazo de salida para la implantación de una nueva forma de entender el mercado de la historieta en España. El tradicional tebeo infantil comienza una larga agonía, que acabaría con la desaparición de la otrora todopoderosa Editorial 
Bruguera en 1986, quedando sustituido en el tejido industrial por las nuevas empresas que se dedican al cómic adulto: Nueva Frontera, Toutain, Norma Editorial o La Cúpula, que establecen un amplísimo abanico de títulos (hasta una treintena en 1982) que recorren toda tipo de géneros y temáticas (Lladó, 2001). Su éxito es fulgurante y sus ventas acompañan: se estima que algunas de las publicaciones más importantes, como 19840 El Vibora podían superar ampliamente los 50.000 ejemplares mensuales, codeándose en importancia en los quioscos con las revistas de cualquier otra temática e incluso teniendo representaciones institucionales con dieron lugar a no pocas controversias (Hernández-Cava, 1988). Las revistas se acompañaron, al igual que en el modelo francés, de la generalización del modelo de álbum, en el que se publicaban recopiladas las obras que se habían serializado en la revista mensualmente. Estos álbumes no tenían grandes tiradas y, rara vez tenían contenidos originales no publicados previamente en revista. Las revistas fomentaron, además, la presencia del autor español, generando un respeto hacia su figura como pocas veces se recordaba (Guiral, 1985)

El surgimiento de la revista de cómics dirigido a los adultos se produce en paralelo a la implantación definitiva del modelo de comic-book americano. Tras años en los que su distribución había sido monopolizada por la editorial Vértice (después transformada en Surco Ediciones), la franquicia Marvel aterriza definitivamente en la editorial Planeta, que a través de su división Forum comenzará una constante -y exitosa - campaña de implantación. Frente a la revista dirigida a público adulto, que podía alcanzar precios de hasta 250 pesetas (1,5 euros), el formato comic-book español (ligeramente superior al americano en tamaño y con 32 páginas) costaba apenas 75 pesetas (unos 0,45 euros), posicionándose rápidamente entre el público juvenil y favoreciendo que otras editoriales usasen ese formato, como Zinco con la franquicia de DC Cómics.

Por su parte, el cómic infantil quedará reducido de forma drástica a los flecos de Bruguera que son absorbidos por el Grupo editorial Zeta y reconvertidos en Ediciones B, que estructurará toda su estrategia alrededor de las rentables creaciones de Francisco Ibáñez.

Sin embargo, esta efervescencia editorial, conocida como el boom de los ochenta, se hundiría en la segunda mitad de la década de los ochenta: en apenas unos años, el modelo industrial español basado en la revista desaparece. Editoriales como
Nueva Frontera o Toutain no resistirán una crisis que dejará las revistas reducidas a apenas unas cuantas cabeceras como CIMOC o El Víbora. Las razones son todavía un misterio: aumento incontrolado del precio del papel, saturación del mercado, excesiva atomización de las revistas que apenas mostraban contenidos mínimamente interesantes para el lector, la competencias de las nuevas formas de entretenimiento, etc (Pons et al., 2007). Cualquiera de las causas tiene potencial para ser origen de la crisis y el denominado "BOF" de las revistas (Cara, 1990), pero no se debe dejar de lado un profundo cambio en la tipología del comprador, que ha evolucionado y dejado atrás el propio concepto de publicación fascicular de calidad atraído por nuevos formatos más inmediatos en tomo o mucho más baratos. Sin embargo, mientras el tejido industrial francés pudo cambiar hacia un modelo de publicación directa en álbum, el español se trasladó directamente al comic-book. Según los datos del anuario de 1989 de la revista Krazy Cómics, se publicaron en ese año 242 publicaciones en formato monográfico, incluyendo desde el álbum tradicional a un formato nuevo, el denominado prestige, básicamente un álbum en rústica pero de tamaño comic-book y que venía importado desde los EE UU (Pérez-Navarro, 1990). Los datos de comic-books no se han recopilado, pero consultado los checklists ${ }^{2}$ de las ediciones de ese año, se pueden estimar en casi 300 los títulos editados en ese formato, repartidos por diferentes series. Editoriales como Toutain o Norma intentarían la adaptación de sus publicaciones a este formato, sin éxito.

La década de los ochenta cerrará de forma radicalmente distinta a como empezó: frente a un casi monopolio de revistas para adultos con editoriales como Nueva Frontera 0 Toutain como principales exponentes, a una preponderancia casi absoluta del formato comic-book con Forum y Zinco.

Al igual que en las décadas anteriores, el quiosco sigue siendo el principal canal de distribución de cómics durante los años ochenta, con la tímida incursión de las librerías especializadas.

\section{EL CAMBIO DE UN MODELO, LOS AÑOS NOVENTA}

La situación del mercado a finales de los ochenta se ahondaría en la década siguiente. El formato álbum todavía conocería una mayor reducción: el anuario de 1993 de la 
editorial Glénat indicaba que tan solo se habían publicado 116 obras en ese formato, casi la mitad que cuatro años antes (Navarro, 1994); las pocas revistas para adultos que sobrevivían desaparecen, quedando solo como exponente de esa época el semanario satírico El Jueves y la revista de inspiración underground EI Vibora.

Este sistema tendrá un aliado importante en el recién nacido circuito de librerías especializadas, apenas testimoniales durante los años ochenta pero que tuvieron un crecimiento geométrico durante la década de los noventa, empujadas por un público coleccionista muy activo y entusiasta que volcará la distribución de tebeos en España. Si hasta ese momento la venta en quioscos era el canal preferente (casi único de distribución), durante esta década se abandonará paulatinamente para trasladarse a la ya extensa red de librerías especializadas que se crea.

La industria del tebeo en España parece circunscribirse a las publicaciones de género de superhéroes, comandadas por la editorial Zinco y una todopoderosa Forum, pero precisamente esta monopolización presenta una quiebra importante: son publicaciones que se basan en el franquiciado, editando material extranjero. El autor español, que vivía una euforia desconocida gracias al formato revista, sufre una brutal recesión en sus posibilidades de publicación. En ese panorama, comienzan a aparecer experiencias e iniciativas de autogestión editora, favorecidas por el abaratamiento de las tecnologías de diseño e impresión, que cristalizarán en la aparición de pequeñas editoriales centradas en intereses muy específicos. Empresas como Edicions de Ponent, Sins Entido o Inrevés son la cabeza visible de un movimiento editorial que se creará alrededor de la librería especializada como canal de distribución, recogiendo el espíritu rompedor y experimental de las publicaciones amateurs 0 fanzines, ahora ya profesionalizados como prozines. Si bien comienzan editando revistas (NSLM, El Ojo Clínico), pronto se convertirán en editoriales que hacen uso tanto del formato tradicional en álbum como de la denominada novela gráfica, un formato libro cuya denominación ya se había usado en España desde los años cuarenta (Barrero, 2008), pero que viene modificada por las connotaciones autorales que alcanza en los EE UU. durante los años noventa (García, 2010).

Hay que resaltar la llamativa aparición del fenómeno manga durante esta década. Al abrigo del éxito de la serie de animación Dragon Ball, la editorial Planeta DeAgostini publicó un coleccionable que transformaba el manga original de Akira Toriyama al formato de comic-book semanal, recibiendo una respuesta del público sin precedentes. Según algunas informaciones no contrastadas, la colección podría haber llegado a ventas de 150.000 ejemplares semanales entre su edición castellana y catalana. Un éxito que recordaba los tiempos de la efervescencia del cuadernillo de aventuras y que provocó un aluvión de títulos de manga, publicados en formato prestige. Un llamado boom del manga que, visto con la distancia, tan solo fue un boom de Dragon Ball. El resto de títulos que editaban la misma editorial Planeta, Ediciones B o Glénat no alcanzaron en ningún caso la repercusión del manga de Toriyama, pero abrieron un camino que lentamente convertiría al manga en una parte fundamental de la industria durante la década siguiente.

\section{LA PRIMERA DÉCADA DEL SIGLO XXI: DEL ENTUSIASMO A LA CRISIS}

Si bien la falta de datos reales de facturación, tiradas y ventas siguen sin conocerse, durante esta década por primera vez se puede hacer un análisis cualitativo más en profundidad gracias a los datos que la Federación de Gremios de Editores de España (FGEE) ha ido publicando en los ya citados informes anuales sobre Comercio Interior del Libro en España, así como la labor de análisis de mercado a partir de los datos de novedades editoriales publicados por FICOMIC que ha venido realizando de forma habitual la página web La Cárcel de Papel ${ }^{3}$ desde el año 2003 y que han tenido reflejo en los anuarios publicados por la Asociación de Autores de Cómic de España en 2006 (Harguindey, 2006) y 2008 (Pons, 2008).

Hay que establecer que, en cualquier caso, un análisis sobre los títulos editados establece un panorama sesgado de la realidad editorial del mercado español, que solo puede ser establecido a partir de las cifras de venta. Este análisis se debería hacer desde los datos de la FGEE, que sí aporta datos cuantitativos de facturación. Sin embargo, estas cifras deben ser analizados con precaución: hay una clara diferencia entre las novedades anuales que presenta el estudio de la FGEE y las que se derivan del estudio de la AACE, llegando a una desviación superior al ciento por ciento. La tabla 1 muestra estas discrepancias. 


\begin{tabular}{|l|c|c|c|c|c|c|c|c|c|c|}
\hline & 2000 & 2001 & 2002 & 2003 & 2004 & 2005 & 2006 & 2007 & 2008 & 2009 \\
\hline Títulos editados según FGEE & 457 & 581 & 334 & 574 & 1.070 & 1.139 & 1.220 & 1.582 & 1.582 & SD \\
\hline Títulos editados según elaboraciones propias y AACE & SD & 1.348 & 1.329 & 1.553 & 1.979 & 2.236 & 2.439 & 2.453 & 2.850 & 2.170 \\
\hline
\end{tabular}

Tabla 1. Diferencias en el número de títulos editados según los informes de la FGEE y los datos de elaboración propia a partir de los listados de novedades de FICOMIC. (SD: sin datos).

Estas profundas diferencias hacen que todo el análisis de facturación posterior de la FGEE deba ser estudiado con sumo cuidado a la hora de extraer conclusiones. En cualquier caso, es evidente el espectacular aumento que ha vivido la industria del cómic durante esta década. Tan solo en títulos publicados a lo largo del año se observa un aumento del 200 por ciento en una década. Una progresión espectacular que confirma un aumento continuado sin precedentes del sector en la historia del tebeo español. Este aumento puede ser fundamentado en varias claves:

- El profundo cambio de la percepción social de la historieta que se ha producido durante esta década, impulsado por la creación de un Premio Nacional de Historieta en 2007.

- La generalización del formato "novela gráfica", que junto a un nuevo tipo de narrativa más adulta proveniente de las nuevas corrientes autorales ha favorecido su inclusión en las grandes superficies y librerías generalistas.

- La eclosión del manga como elemento fundamental de atracción de nuevos lectores y, sobre todo, nuevas lectoras4.

- La generalización de la presencia del tebeo en la prensa general, con una imagen alejada de la percepción infantil que hasta ahora se tenía.

- El impacto de las adaptaciones cinematográficas de populares series de superhéroes y otros títulos de cómic, tanto americanos como españoles o europeos.

- El conjunto ha dado lugar a un panorama estable dentro del sector industrial del libro, que distingue básicamente entre cuatro fenómenos editoriales durante esta década:

- Editoriales que basan su producción en franquiciados de género superheróico americano. Suelen ser grandes grupos editoriales multinacionales (Planeta DeAgostini, Panini Cómics).

- Editoriales basadas en la publicación de franquiciado manga (Ivrea, Glénat, M angaline...). En algunos casos se pueden encontrar una mayor diversidad de catálogo, como en la editorial Glénat, que compagina una amplia oferta de manga frente a ediciones de autores españoles 0 europeos.

- Editoriales de pequeño tamaño, que basan su producción en la importación de títulos americanos y la producción propia de autores nacionales, generalmente en formato novela gráfica (Sins Entido, Astiberri, Edicions de Ponent...).

- El fenómeno Ibáñez explotado por Ediciones B, único caso en el mundo de autor que tiene más de 170 títulos en catálogo reeditados con alta frecuencia.

Sin embargo, el eufórico optimismo de este análisis choca frontalmente con los datos de 2009. La profunda crisis internacional derivada de la crisis financiera ha impactado brutalmente en la industria española y el desplome es de gran importancia: tras años de aumentos continuados de más del 20 por ciento en el número de novedades anuales, el año 2009 presenta un retroceso de casi un 30 por ciento. Una disminución a la que se añade la pérdida de muchas pequeñas editoriales que aparecieron en 2007 y 2008 y que durante 2009 han parado su actividad, ya sea como precaución o porque se han visto obligadas a cerrar sus puertas ante la crisis. Es evidente que esta disminución debe ser estudiada no sólo en términos de catálogo de títulos, sino en términos de facturación. La tabla 2 muestra la evolución de la facturación durante esta década para el sector del cómic según los datos de la FGEE.

\begin{tabular}{|l|c|c|c|c|c|c|c|c|c|c|}
\hline & 2000 & 2001 & 2002 & 2003 & 2004 & 2005 & 2006 & 2007 & 2008 & 2009 \\
\hline Cifras de facturación (millones de euros) & 124,15 & 111,47 & 94,06 & 88,27 & 96,65 & 98,78 & 83,03 & 77,05 & 84,87 & 79,30 \\
\hline
\end{tabular}

Tabla 2. Facturación del sector del cómic en España según los informes de la FGEE. 
Sorprendentemente, se obtiene una bajada continuada de la facturación, contraria a la percepción que se tiene de un aumento de presencia del cómic en los circuitos comerciales. Estas diferencias pueden tener como explicación las diferencias mostradas en la tabla I: los datos de los informes de FGEE recogerían las novedades de las editoriales más importantes del sector, dejando de lado el impacto que están teniendo las pequeñas editoriales en la industria del cómic español. Se puede hacer un ejercicio estimativo para establecer el posible impacto de estas diferencias. Según diversas entrevistas a editores, la tirada media de una novela gráfica en España podría estar alrededor de los 1.500-2.000 ejemplares. Asumiendo una venta completa de la tirada y un precio promedio de 9 euros (según los datos de FGEE), la diferencia de 1.268 títulos en 2008 podría suponer entre 17,12 y 22,84 millones de euros de diferencia en la facturación. Entre un 20,2 y un 26,9 por ciento al alza respecto a las cifras oficiales de la Federación de Gremios de Editores. Si bien esta estimación es puramente especulativa, deja en evidencia que las cifras de facturación reales deben ser bastante más altas que las presentadas por la FGEE, pero no en una relación lineal respecto a la desviación de más del 200 por ciento en el número de títulos. De nuevo, el desconocimiento de las cifras reales de venta o de las tiradas deja en el aire todo posible análisis. Hay declaraciones que hacen pensar en el fuerte impacto del manga en la facturación total: declaraciones del editor J oan Navarro en su blog indican que títulos como Naruto podrían haber llegado a superar los 30.000 ejemplares de distribución (con un lento descenso que no impediría que en 2009 fuera el manga más vendido de esta editorial con 14.786 ejemplares 5 ). Un impacto que ha sufrido especialmente la crisis de 2009: según estimaciones de la editorial, el manga ha disminuido casi un 30 por ciento sus ventas durante ese año $0^{6}$. Esta disminución podría indicar que el sector del manga ha sido el más afectado por la crisis de final de esta década, coincidiendo con la declaración de otros editores como J osé Luis Córdoba (Panini Cómics), que avalan una gran estabilidad del mercado de comic-book americano ${ }^{7}$.

Estas tendencias se pueden comprobar analizando la evolución de la segmentación de las novedades en función de su procedencia geográfica. Como se puede ver en la figura 1, la supremacía absoluta del cómic de procedencia estadounidense durante esta década solo ha tenido como oponente el manga japonés, que ha aumentado lentamente su cuota desde apenas un 11 por ciento del total de títulos editados en 2001 (Harguindey, 2006), hasta el 33 por ciento que alcanzó en 2008, con una espectacular caída hasta el 25 por ciento en 2009 , un porcentaje de disminución de casi un 25 por ciento coincidente con las estimaciones del editor J oan Navarro anteriormente citadas. Sorprende que esa disminución coincida con el primer ascenso de la cuota de títulos de autores españoles en una década. Tras una lenta pero constante disminución del porcentaje de títulos autóctonos desde el 17 por ciento de 2003 hasta el 10 por ciento de 2008, en 2009 se produce un espectacular aumento hasta el 15 por ciento. Este cambio podría ser debido a la aparición de coleccionables de quiosco dedicados al tebeo español y a la corriente de reedición de clásicos como Esther, de Purita Campos, a lo que hay que añadir las diferentes líneas dedicadas específicamente a autores españoles que lanzaron durante 2009 editoriales como Norma, Planeta DeAgostini o Glénat. Sin embargo, esta debilidad aparente del cómic español puede ser falsa: pese a que el número de novedades sea escaso, el impacto de éxitos editoriales como la citada obra de Purita Campos o las millonarias ventas de Mortadelo y Filemón en sus múltiples versiones y reediciones podrían establecer que sea el tebeo autóctono el de mayor facturación en España.

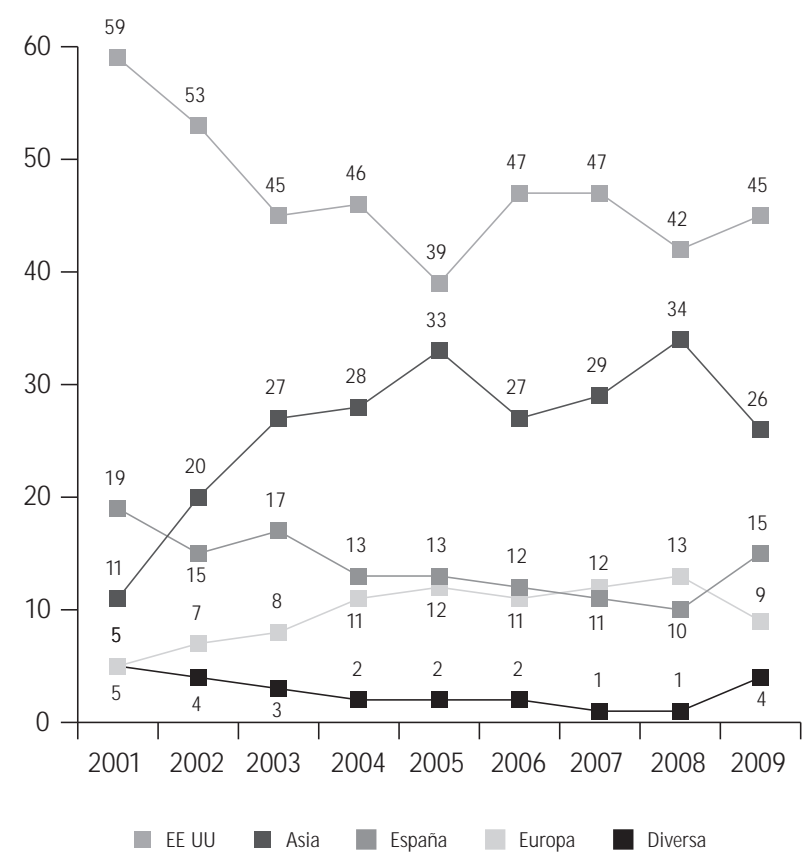

Figura 1. Evolución de los porcentajes de novedades según la procedencia geográfica de los cómics.

ARBOR CLXXXVII 2EXTRA 2011 265-273 ISSN: 0210-1963

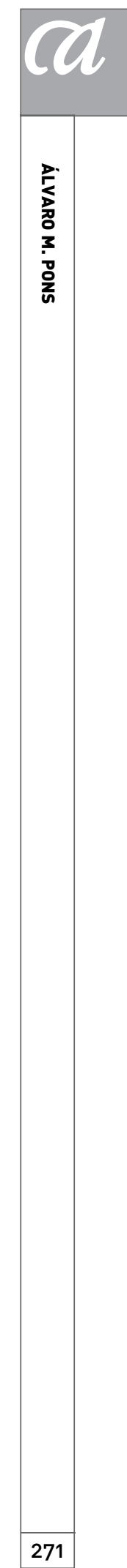


Es también interesante analizar cómo ha evolucionado el formato fundamental de publicación en España durante esta década, ligado a la consolidación de un formato libro con el que se pueden identificar tanto la novela gráfica, como el tradicional tomo manga (tankoubon) o el tomo recopilatorio de series de inicialmente publicadas en formato de comicbook, generalmente del género de superhéroes. La figura 2 resume esta evolución: desde una posición predominante del comic-book al principio de la década, derivada de la posición monopolista de este formato de tebeo durante

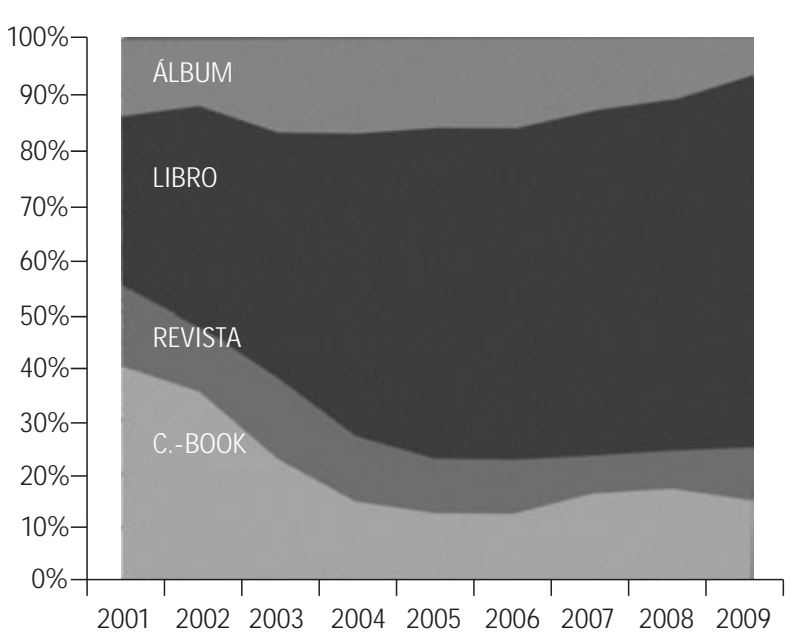

Figura 2. Distribución de novedades por formatos de publicación. la década de los noventa (que incluyó tanto las series tradicionales de superhéroes en este formato como multitud de experiencias editoriales, incluyendo las de autogestión de autores españoles, que también eligieron este formato por su economía y sencillez), se ha pasado a una abrumadora posición dominante del libro, que llega a ocupar un 68 por ciento de los títulos publicados durante 2009. De este porcentaje, aproximadamente un 41 por ciento corresponde a tomos de manga japonés. Este cambio consolida, además, un importante cambio de canal de distribución, que ha pasado del quiosco hasta los años setenta a la librería especializada durante los noventa, compartido en la primera década del siglo XXI con la librería generalista y la gran superficie.

\section{¿EL FUTURO ES DIGITAL?}

La volubilidad de comportamiento y la actual situación de crisis de la industria del cómic en España hace muy complejo realizar cualquier predicción a corto 0 medio plazo. Parece lógico pensar que existirá un nuevo vuelco hacia la publicación en medios digitales, favorecida por la aparición de dispositivos de visualización que pueden dar una buena representación de la página en color, pero es todavía una incógnita saber cómo resistirá la industria española este complejo cambio que puede dar lugar a una profunda transformación del tejido industrial implicando a distribuidores, libreros y editores.

\section{NOTAS}

1 Se pueden consultar de forma gratuita en la página web de la Federación: http://www.federacioneditores. org

2 Los checklists son listados mensuales que incluían muchos de los comicbooks de la época.

3 La Cárcel de Papel: http://www. lacarceldepapel.com

4 Hay que recordar que el perfil de lector en España corresponde a una mujer joven. En el informe de "Hábitos de lectura y compra de libros 2009" presentado por la FGEE se establece que el 58,4 por ciento de los lectores son mujeres, en un porcentaje que llega al 70,5 por ciento en el rango de edad de 14-24 años, sector mayoritario hacia el que va dirigido el Ilamado shojo manga o manga juvenil femenino.

5 Dato proporcionado por el propio editor en http://navarrobadia.blogspot.com/2010/01/glenat-mangamas- vendido- del-ano.html

6 Dato del editor en http://navarrobadia.blogspot.com/2010/07/siguenbajando- las- ventas.html

7 Declaraciones en http://www.universomarvel.com/index.php?option= com_content $\&$ task=view $\& i d=6409$ \&ltemid $=30$
Recibido: 19 de septiembre de 2010
Aceptado: 10 de diciembre de 2010 


\section{BIBLIOGRAFÍA}

Altarriba, Antonio (2001): La España del tebeo. La historieta española de 1940 a 2000. Madrid: Espasa-Calpe.

BARRERO, Manuel (2008): La novela gráfica. Perversión genérica de una etiqueta editorial. En Literaturas.com: http://www.literaturas.com/v010/se c0712/suplemento/Articulo8diciembre.html

Beaum Ont, José (1976): "Donde hay un tebeo no habrá necesariamente un libro", en el El País, del 31 de diciembre de 1976.

Cara, Diego (1990): "Al otro lado del quiosco. Sobre la voceada crisis", en Anuario 1989 Krazy Cómics. BarceIona: Editorial Complot.

CIRICI, Alexandre (1977): La estética del franquismo. Barcelona: Gustavo Pili.

García, Santiago (2010): La novela gráfica. Bilbao: Astiberri.

GuIRAL, Antoni (1985): 1983/84: Series de producción autóctona para una temporada prolifica. Fancomics 1: 17-20.
Harguindey, Breixo (2006): "El estado del cómic. Informe 2001-2005", en Anuario de la historieta 2005. Valencia: AACE.

Hernández-Cava, Felipe (1988): Apuntes para la historia de un tebeo subvencionado: la experiencia de Madriz. Neuróptica 5: 54-63.

LLAdó, Francesca (2001): Los cómics de la transición. Barcelona: Glénat.

Martín, Antonio (1978): "Auge del cómic bajo la dictadura 1923-1930", en Historia del cómic español: 18751939. Barcelona: Gustavo Pili.

- (2000): Apuntes para una historia de los tebeos. Barcelona: Glénat.

- (2003): Breve panorama de la industria editorial del cómic en España. Educación y Bibliotecas 134: 79-85.

Molx, Terenci (1968): Los cómics, arte para el consumo y formas pop. Barcelona: Llibres de Sinera.

NavarRo, J oan (1985): Los tebeos en España durante los años 60 . Neuróptica 3: 112-121.
- (ed.) (1994): 1993: Un año de tebeos. Barcelona: Glénat ediciones.

Pérez-Navarro, Francisco (1990): El "prestigio" american. Krazy Comics 4: 20-21.

Pons, Álvaro (2003): Between Avant-Garde and Commerciality: the dochotomy of new alternative publishing houses companies in Spain. International Journal of Comic Art, 5:138-153.

- (2006): Unha arte democrática: o tebeo como espello da sociedade dende o século XIX até os 70. Boletín Galego de Literatura, 35: 81111.

- (2008): "Los tebeos en España en el 2007", en Anuario de la historieta 2006-7. Valencia: AACE.

Pons, Álvaro, PorCel, Pedro y Sorni, Vicente (2007): Viñetas a la luna de valencia: La historia del tebeo valenciano 1965-2006. Onil: Edicions de Ponent.

PorCEL, Pedro (2002): Clásicos en Jauja: Ia historia del tebeo valenciano. Onil: Edicions de Ponent. 